\title{
Competency Standards for Emerging Hydrogen Related Activities
}

\author{
Richard Skiba \\ LRES Training Management, Melbourne, Australia \\ Email: richard@skiba.com.au
}

How to cite this paper: Skiba, R. (2020) Competency Standards for Emerging $\mathrm{Hy}$ drogen Related Activities. Open Journal of Safety Science and Technology, 10, 42-52. https://doi.org/10.4236/ojsst.2020.102004

Received: April 2, 2020

Accepted: May 15, 2020

Published: May 18, 2020

Copyright () 2020 by author(s) and Scientific Research Publishing Inc. This work is licensed under the Creative Commons Attribution International License (CC BY 4.0).

http://creativecommons.org/licenses/by/4.0/

\begin{abstract}
As hydrogen use as a fuel gains momentum and becomes a component of many nation's economies, there is a growing need for identification of the skills and knowledge required by workers undertaking hydrogen related activities. This paper considers the activities in the industry and qualifies some of the core competencies required for the emerging workforce. The core competencies are considered specifically from the perspective of working with hydrogen rather than other gases, which in most cases have well developed competency standards, many of which can be applied to the hydrogen industry. The paper focuses on training as it is applicable at a vocational education and training sector level, such as technicians, trade workers and transportation workers, rather than the job roles that require degree or above level qualifications. For many decades, hydrogen has been used extensively in the process industries (e.g. refineries and ammonia synthesis) and experience has shown that it can be handled safely in industrial applications as long as appropriate standards, regulations and best practices are being followed [1]. Relevant training will contribute to the safe handling and use of hydrogen in its new applications. A number of general competency standards for work in hydrogen related activities are presented and these can be used to be integrated into existing vocational education and training frameworks.
\end{abstract}

\section{Keywords}

Hydrogen Related Activities, Competency Standards, Health and Safety, Vocational Education

\section{Introduction}

\subsection{Industrial Use of Hydrogen}

Energy markets across the globe are undergoing substantial change, driven by 
the need to reduce carbon emissions while meeting growing demand for energy [2]. Hydrogen is a flexible, safe, transportable and storable fuel that can be used to power vehicles and generate heat and electricity. There is significant global movement toward utilisation of hydrogen as a fuel and globally, hydrogen makers now produce about 70 million tonnes of hydrogen per year [3].

Hydrogen is an energy-efficient, low-polluting fuel. The US Energy Information Administration [4] reports that nearly all of the hydrogen consumed in the United States is used by "industry for refining petroleum, treating metals, producing fertilizer, and processing foods". US petroleum refineries use hydrogen to lower the sulphur content of fuels. They also outline that the National Aeronautics and Space Administration (NASA) began using liquid hydrogen in the 1950s as a rocket fuel, and NASA was one of the first to use hydrogen fuel cells to power the electrical systems on spacecraft.

Hydrogen fuel cells can also be used to produce electricity for a range of applications. They do this by combining hydrogen and oxygen atoms. The hydrogen reacts with oxygen across an electrochemical cell similar to that of a battery to produce electricity, water, and small amounts of heat [4]. Small fuel cells can power laptop computers and even mobile phones, and military applications. Large fuel cells can provide electricity for backup or emergency power in buildings and supply electricity in places that are not connected to electric power grids. The US Energy Information Administration [4] notes that at the end of October 2019 , there were approximately 80 fuel cell power plants operating in the United States.

IEA [5] outlines "supplying hydrogen to industrial users is now a major business around the world". They report that demand for hydrogen, which has grown more than threefold since 1975 , continues to rise with $6 \%$ of global natural gas and $2 \%$ of global coal going to hydrogen production. AZoCleantech [6] illuminates that given that hydrogen does not exist on Earth as a gas, it must be separated from other compounds. Two of the most common methods used for the production of hydrogen are electrolysis or water splitting and steam reforming. Steam reforming is used in industries to separate hydrogen atoms from carbon atoms in methane.

Electrolysis involves passing an electric current through water to separate water into its basic elements, hydrogen and oxygen and hydrogen is then collected at the negatively charged cathode and oxygen at the positive anode [6]. Hydrogen production using renewable electricity is growing rapidly and most commonly, electricity from renewable sources such as wind or solar power is used to drive the electrochemical dissociation (electrolysis) of water to form hydrogen and oxygen [7].

The Hydrogen Strategy Group [7] outlines that hydrogen, from a consumer perspective, is a gas much like natural gas that can be used to heat buildings and power vehicles. It can be mixed with natural gas as a way to lower greenhouse gas emissions for space heating, water heating and cooking. They further outline that it can be used as a biofuel in cars or stored in fuel cells as an alternative to 
batteries for electric cars which will require new skills in handling, storing, and using hydrogen. The Hydrogen Strategy Group also identify that from an environmental perspective, hydrogen is unique among liquid and gaseous fuels in that it emits absolutely no $\mathrm{CO}_{2}$ emissions when burned.

Australian Industry Standards [8] note that hydrogen can be safely added to the existing infrastructure and appliances at $10 \%$ volume without making any changes to pipes or regulations. Hydrogen can be extracted from fossil fuels and biomass, from water, or from a mix of both [5]. Natural gas is currently the primary source of hydrogen production accounting for about $6 \%$ of global natural gas use. IEA [5] note that gas is followed by coal, due to its dominant role in China, and a small fraction is produced from the use of oil and electricity.

\subsection{Evolving Need for Training in Hydrogen Related Activities}

There is a growing identification in Australia, through its industry, that there is a current need for training and competency standards involved in the safe handling and storage of hydrogen, particularly as Australia establishes itself as a key supplier of hydrogen. Australian Industry Standards [8] through its industry stakeholder consultations identifies that Australia has the potential to establish itself as a key supplier of hydrogen whilst countries such as China, South Korea, Singapore, and Japan are relying on hydrogen as a cost-effective route to reducing emissions. They identify that there is a current movement for industries to seek out new energy sources based on environmental concerns and hydrogen can be seen as a viable alternative, particularly since as it is a very versatile, low cost, and low emission fuel.

Australian Industry Standards [8] identifies that the workforce requires upskilling and retraining especially in hydrogen storage and safe handling. They refer to the COAG Hydrogen Council Working Group which has "recommended training and educational programs to both build the necessary skills for the hydrogen industry and build community understanding and support for hydrogen". They further posit that "with appropriate skills training and accreditation programs, the Australian gas industry is poised to maximise growth opportunities in the hydrogen value chain" and that this would enable "an economically sustainable hydrogen sector, helping to address concerns around energy security and supply" [8].

Referring to the International Energy Agency (IEA), Australian Industry Standards [9] notes that activities which involve the use of hydrogen, can pose some explicit public safety risks. As such, these activities require specific measures to ensure this risk is appropriately managed and contained. The chemical composition of hydrogen means that heating, or reactions with air, halogens or strong oxidants can all significantly increase the risk of an explosion hazard Australian Industry Standards [9]. Some of the required safety measures are addressed by the COAG Energy Council released Australia's National Hydrogen Strategy [2] with an identification of the maintenance of a safe environment for the community and emergency services personnel. The COAG document identi- 
fies that more work needs to be done in skills development in this field. The training process commences with an identification of the skills needed in the gas and also public safety industries, and structuring these into competency standards that can be utilised as a foundation for training programs.

Bezdek [10] refers to a study by the US Department of Energy (DOE) that found "training for new skills may be needed across a wide spectrum of industries and that training and retraining programs may be needed to help ensure that the US workforce possesses appropriate skills and that sufficient numbers of trained personnel are available to support the hydrogen economy".

\subsection{Hydrogen Related Activities}

Hydrogen related activities include those related to research, production, storage, transportation and distribution. They also include development and fitting hydrogen based systems, such as fuel cells into vehicles. Bezdek [10] identifies a range of current and new work roles for workers in hydrogen related activities. Within the vocational education and training domain, these include roles such as: Fuel cell manufacturing technician; Fuel cell fabrication and testing technician; Hydrogen energy systems designer; Hydrogen fuel transporter-Trucker; Hydrogen fueling station operator; Hydrogen pipeline construction worker; Fuel cell retrofit installer; Hydrogen vehicle electrician; Hydrogen lab technician; and, Hydrogen energy system installer.

Currently, hydrogen is distributed through three methods: Pipeline; HighPressure Tube Trailers; and Liquefied Hydrogen Tankers. Each distribution method requires specific job roles and safety standards. They all require competency standards as a benchmark such that they can be suitably trained into these roles.

\subsection{Hydrogen Hazards}

Some of the challenges regarding hydrogen include the transportation and storage of liquid hydrogen, hydrogen carriers, pipelines, and hydrogen terminals [9]. Hydrogen Strategy Group [7] outline that "given their combustible nature, all conventional fuels have some degree of risk associated with their use" and "although hydrogen is a different fuel to natural gas and has different combustion characteristics, a preliminary analysis by the Energy Pipelines Cooperative Research Centre indicates its overall risk is similar".

Some considerations include that if hydrogen leaks, it will disperse much more quickly than natural gas and is not as likely to collect in confined spaces, reducing the risk of a gas explosion. Hydrogen ignites at a wider range of concentrations in air with a flammability range is between $4 \%$ and $75 \%$ in air. However, because hydrogen disperses quicker, it is more difficult for it to remain concentrated enough to be flammable. Adequate ventilation and leak detection protocols can mitigate any potential greater risk [7].

Hydrogen flames are more difficult to see than those of natural gas. Hydrogen Strategy Group [7] suggest that this can be addressed by adding a suitable com- 
pound to the hydrogen mix so the flame burns a particular colour, or by using special flame detectors. Hydrogen also reacts differently with metals and it can cause certain metals to become brittle and crack. This risk can be addressed through guidelines on appropriate materials and training on handling hydrogen. Hydrogen Strategy Group [7] summarise that "using any fuel safely relies on preventing the simultaneous unwanted occurrence of three factors: an ignition source (spark or heat), an oxidant (air), and fuel". Suitable training focuses on avoidance of the simultaneous occurrence of these three factors.

\subsection{Hydrogen Work Environment Skills and Knowledge Requirements}

A cautiously optimistic scenario could see an Australian hydrogen industry generate about 7600 jobs and add about $\$ 11$ billion a year in additional GDP by 2050 [2]. There will be a significant demand for training across these jobs including technicians, trades people, engineers and professionals. As such, the range of skills and knowledge requirements are broad and specific to the work role.

In general, as outlined by $\mathrm{H} 2$ Tools [11], all staff who will be working with or around hydrogen should be adequately trained on hydrogen safety procedures. They need to, at the very least, understand hydrogen properties and behaviour, safety requirements for working with or around high-pressure hydrogen gas and cryogenic liquid hydrogen and hydrogen equipment inspection, operation, and maintenance. Health and Safety aspects related to working with hydrogen are core skills and knowledge that should be included in any training program. Also required are first aid procedures and emergency notification and evacuation/response policies and procedures.

Dahoe and Molkov [1] presented a structure for a proposed "International Curriculum on Hydrogen Safety Engineering”. They presented basic, fundamental and applied modules as the framework of training requirements in providing training for the emerging hydrogen economy. The five basic modules include: thermodynamics; chemical kinetics; fluid dynamics; heat and mass transfer; and solid mechanics. There are six fundamental modules: introduction to hydrogen as an energy carrier; fundamentals of hydrogen safety; release, mixing and distribution; hydrogen ignition; hydrogen fires; and, explosions, deflagrations and detonations. The applied modules are intended to provide graduates with the skill-set needed to solve hydrogen safety problems. These include modules: fire and explosion effects on people, structures, and the environment; accident prevention and mitigation; computational hydrogen safety engineering; and, risk assessment.

Individuals who are working in hydrogen related activities need to understand the properties of hydrogen and how it compares to other fuels. The safety mechanisms of hydrogen systems must also be covered and will vary on the work role and relevant hydrogen system. The general skills and knowledge include the fundamentals of hydrogen, hydrogen terminology and technology, potential 
Table 1. General competency standards for those working with hydrogen.

Unit 1-Prepare to work in the hydrogen industry

This competency standard includes an overview of the hydrogen industry, characteristics of hydrogen, relevant mandatory safety regulations and workplace policies, procedures and work practices required for working in the hydrogen industry.

Skills

- applying relevant industry standards, guidelines, codes of practice and regulations

- applying relevant work health and requirements, including applying risk control and safe work methods

- applying sustainable energy principles and practices

- communicating effectively with relevant person/s

- completing relevant workplace documentation

- confirming and following schedule of work and job requirements

- consulting relevant person/s to coordinate work

- dealing with unplanned events/situations in accordance with workplace procedures, in a manner that minimises risk to personnel and equipment

- following hydrogen gas related activity workplace procedures and instructions

- maintaining a clean work area

- obtaining relevant resources and materials to conduct the work

- performing quality checks

- working within agreed timeframes or conditions.

Knowledge

- Systeme Internationale (SI) units and uses within gas utilisation

- sources of energy and heat transfer

- combined gas laws (Charles' and Boyle's Law)

- interrelationship between pressure, volume and temperature

- operation pressure regulators

- procedures/protocols for dealing with unplanned events

- relevant hydrogen industry licensing/regulatory requirements

- relevant industry risk mitigation processes, including risk control and safe work methods

- relevant industry standards, guidelines, codes of practice and regulations

- relevant workplace documentation

- relevant workplace policies, procedures and instructions

- requirements to enter the work area

- statutory authorities and regulatory bodies that operate in the hydrogen industry

- sustainable energy principles and practices

Unit 2-Carry out basic work activities in a hydrogen industry work environment This competency standard includes following workplace procedures to correctly and safely carry out hydrogen industry work activities using appropriate materials, tools and measuring devices.

Skills

- hazard identification and reporting

- implementing risk control measures

- reporting hazards, risks and incidents to relevant person/s

- selecting and using relevant personal protective equipment (PPE)

- carrying out hydrogen gas industry work activities

- cleaning, checking and storing tools, equipment and measuring devices

- communicating effectively with relevant person/s

- completing workplace documentation

- conducting quality and safety checks

- identifying, selecting and using appropriate equipment, tools and measuring devices for relevant work activities

- obtaining job requirements and work instructions

- obtaining relevant resources and materials to conduct the work 


\section{Continued}

Knowledge

- correct selection, safe operation, cleaning and storing of relevant hydrogen industry materials, equipment, tools and measuring devices

- environmental and sustainable energy principles and practices, including techniques to minimise waste

- hazards in the workplace

- hazardous substances and examples from each classification category to include: toxic, harmful, corrosive, irritant, oxidising, extremely flammable

- hydrogen production techniques

- hydrogen production from renewable sources-electrolysis, biofuels, photolysis

- dangers when working in confined spaces

- job specifications and job requirements

- quality and safety checks

- relevant hydrogen industry materials, plans, diagrams, drawings and resources, including graphs and tables

- hydrogen storage techniques

- relevant hydrogen industry regulations, codes and legislation

- relevant machines/plant/equipment

- relevant manufacturer instructions

- relevant person/s to consult to coordinate and finalise work

- relevant workplace policies and procedures

- relevant risk mitigation processes, including relevant PPE, safety plans and work schedules

Unit 3-Comply with environmental policies and procedures in the hydrogen industry This competency standard includes complying with relevant legislations, standards, regulations and codes of practice and their application to relevant workplace tasks in the hydrogen industry and completing relevant work completion documentation.

Skills

- applying environmental control measure and workplace procedures

- applying relevant industry standards, guidelines, codes of practice and regulations

- applying relevant work health and safety requirements

- applying sustainable energy and environmental principles and practices

- completing work and relevant environmental documentation, reports, records and forms

- complying with environmental policies and procedures

- controlling and minimising the impact of an environmental incident

- dealing with non-routine events, accidents and emergencies in accordance with workplace procedures

- following environmental incident review procedures

- following workplace procedures

- identifying potential and actual environmental hazards and impacts

- identifying, interpreting and applying relevant environmental procedures

- making recommendations to prevent occurrence

- minimising waste and damage to the environment

- preparing to comply with environmental policies and procedures

- reviewing control measures

- selecting and using environmentally beneficial equipment and materials

Knowledge

- causes of environmental damage including chemicals, oil, water contamination, carcinogenic agents, gases, dusts, waste contamination and noise

- environmental compliance in a utilities industry work environment

- transport methods as compressed gas, as liquid or via ammonia or naphthenes

- hydrogen transportation by pipeline

- environmentally beneficial equipment and materials

- environmentally safe waste disposal

- relevant environmental legislation, regulations, standards, acts and codes of practice

- relevant manufacturer specifications

- relevant procedures to control and minimise the impact of an environmental incident

- relevant workplace documentation includes records, and incident reporting

- relevant workplace policies and procedures, including environment protection workplace procedures

- response to workplace environmental incidents

- role of regulatory bodies in monitoring environmental activities, risk and incident compliance 


\section{Continued}

Unit 4-Apply workplace health and safety regulations, codes and practices in the hydrogen industry

This competency standard includes responsibilities and application at operative levels for health and safety, risk management and adherence to safety practices in the hydrogen supply industry.

Skills

- applying relevant work health and safety occupational health and safety requirements

- applying safe working practices

- applying regulations and codes of practices in the workplace

- checking tools and equipment for safety and correct operation

- isolating plant/machinery/equipment

- completing relevant workplace documentation

- dealing with workplace accidents, emergencies and fires within scope of responsibility

- following and applying work procedures and instructions as they apply to risk control measures

- identifying hazards and implementing and monitoring control measures

- obtaining applicable work permits, clearances and isolation permissions prior to entering the work area

- participating regularly in consultation processes

- preparing to enter a hydrogen supply work area in accordance with workplace procedures

- reporting hazards to relevant person/s in accordance with workplace procedures

Knowledge

- appropriate fire extinguisher for a given type of fire and its use

- commonly used workplace safety signs

- hierarchy of hazard control measures

- hazards associated with hydrogen supply work environments

- procedures used to control risks

- principles of risk assessment

- safe manual handling principles

- workplace emergencies that pose a threat to health and safety and suitable procedures for an emergency workplace evacuation

- chemicals in the workplace, including: hazardous substances and dangerous goods, safe storage procedures and purpose and interpretation of safety data sheet (SDS), types

- and classes: fuelled, flammable and other relevant gases, effects of gases on the human body, common causes of gas accidents and ignition, products of (complete and incomplete) combustion, precautions that can minimise the chance of gas accidents and ignition

- requirements for working with gases, fire protection and control/extinguishing

- hydrogen reactivity with metals

- requirements for working in a designated hazardous area

- relevant industry standards, legislation, guidelines, codes of practice and regulations

- relevant manufacturer specifications

- relevant safe work method statements (SWMS)/job safety assessments or risk mitigation processes

- relevant legislated requirements

- relevant work area access, clearances and isolation permissions/permits

- relevant workplace documentation

- relevant workplace policies and procedures

- techniques to check tools and equipment for safety and correct functionality

- techniques to monitor implemented control measures

- working safely with electricity

- working safely with gases

Unit 5-Carry out hydrogen transport and loading

This competency standard includes following workplace procedures to correctly and safely transport and transfer hydrogen. This includes recognising the characteristics of hydrogen and hydrogen tube trailers/tankers to ensure the safe transfer and transport of fuel, conducting pre-trip inspections, performing tube trailer/tanker loading tests and transporting load to customer site. It also includes preparing a site to accept delivery, managing delivery, completing post-delivery activities and following emergency procedures. 


\section{Continued}

Skills

- applying precautions and required actions to minimise, control or eliminate identified hazards associated with hydrogen transportation

- communicating effectively with others in the workplace

- completing documentation relating to operating a hydrogen tube trailer

- completing post-delivery activities

- correctly positioning a tube trailer/tanker when loading and unloading

- discharging hydrogen to storage system

- identifying tube trailer/tanker and product compatibility

- identifying product correctly, and placarding tube trailer/tanker accordingly

- implementing contingency plans

- interpreting and following operational instructions and prioritising work

- loading hydrogen

- meeting customer requirements when delivering hydrogen to customer site

- modifying activities depending on operational contingencies, risk situations and environments

- monitoring and anticipating traffic hazards and taking appropriate action

- monitoring performance of tube trailer/tanker, its trailers and its equipment and taking appropriate action as required

- $\quad$ operating and adapting to differences in equipment in accordance with standard operating procedures

- preparing a route to maximise safety and efficiency, and to meet organisational route requirements

- $\quad$ reading and interpreting relevant instructions, procedures, information and signs

- safely unloading hydrogen at a customer site

- $\quad$ selecting and using required personal protective equipment, conforming to industry

- $\quad$ and work health and safety standards

- undertaking a pre-trip inspection of a tube trailer/tanker

- using eco-driving techniques when operating a tube trailer/tanker

- working systematically with required attention to detail without injury to self or others, or damage to goods or equipment

Knowledge

- compressed hydrogen storage on board in tanks based on type IV carbon-composite technology

- $\quad$ processes for transporting gaseous hydrogen by tube trailers

- $\quad$ process for transporting liquid hydrogen road tanker

- $\quad$ hydrogen storage pressures

- use of cryogenic conditions in insulated tanks

- potential for boil-off during transportation

- hydrogen embrittlement caused by the interaction of hydrogen atoms with the crystal lattices within steel

- factors causing of tube trailer/tanker accidents and incidents

- effects of weight distribution on load behaviour and vehicle stability

- efficient driving techniques and eco-driving considerations

- factors involved in trip preparation

- factors that may cause traffic delays and diversions, and related action that can be taken

- fatigue management strategies

- how to select and use required personal protective equipment, conforming to industry and work health and safety standards

- $\quad$ procedures to be followed in a driving emergency and response to an emergency using a company transport emergency response plan

- properties of hydrogen

- relevant dangerous goods (DG) information for using tube trailer/tankers

- relevant legislation and industry workplace procedures for transporting hydrogen

- relevant organisational requirements including policies and procedures

- relevant state/territory roads and traffic authority road rules, regulations, permit and licence requirements

- relevant health and safety and environmental procedures and regulations relating to fuel tanker operations

- techniques and procedures for loading and unloading a tube trailer/tanker safely

- techniques for safe delivery of hydrogen to a customer site

- techniques to continually identify and mitigate environmental risks

- workplace documentation

- $\quad$ workplace driving and operational instructions

- working at heights procedures for tube trailer/tanker drivers 
hazards and potential protective measures. These general skills and knowledge should include carrying out appropriate incident response actions. Those who are working with hydrogen powered vehicles also need to recognize and identify hydrogen vehicles, stationary power generators, storage containers, and refuelling equipment. A Framework for general competency standards for those working with hydrogen is provided as Table 1 . The table provides a basis from which learning outcomes or performance element/criteria can be developed given the variation in vocational education and enterprise training systems globally. The key module topics as presented by Dahoe and Molkov [1] have been integrated into the contrived competency standard framework.

A number of competency standards would also be required to cover those involved with fitting and maintaining hydrogen fuel cell electric vehicles as this technology evolves and uptake of its use increases.

Trinder [12] illuminates that "Competency Standards are used by professions and governments to define the qualifications required for professionals to practise in a profession or discipline". Trinder further defines competence as "the ability to perform activities within an occupation; to function as expected for employment; and the ability to do a job under a variety of conditions, including the ability to cope with contingencies". Competence for those who are employed in the hydrogen industry is critical to the safety of the systems those workers creating, installing and maintaining them.

\section{Conclusion}

Hydrogen safety training should be provided to all employees who handle hydrogen or materials from which hydrogen can be evolved. Employers should ensure that workers have access to proper training to do their jobs safely. Training should be based on a competency standard designed specifically around hydrogen related activities and the hazards related to these activities. Aside from job role specific competency standards, uniform general competency standards can include: preparing to work in the hydrogen industry, work practices in the hydrogen industry, complying with environmental policies and procedures, application of health and safety and transporting hydrogen.

\section{Conflicts of Interest}

The author declares no conflicts of interest regarding the publication of this paper.

\section{References}

[1] Dahoe, A.E. and Molkov, V.V. (2006) On the Development of an International Curriculum on Hydrogen Safety Engineering and Its Implementation into Educational Programmes. WEHC, 4.

[2] COAG Energy Council Hydrogen Working Group (2019) Australia's National Hydrogen Strategy. Commonwealth of Australia.

[3] International Energy Agency (2019) The Future of Hydrogen. 
https://webstore.iea.org/download/summary/2803?fileName=English-Future-Hydr ogen-ES.pdf

[4] U.S. Energy Information Administration (2020) Hydrogen Explained: Use of Hydrogen. https://www.eia.gov/energyexplained/hydrogen/use-of-hydrogen.php

[5] IEA (2019) The Future of Hydrogen. IEA, Paris. https://www.iea.org/reports/the-future-of-hydrogen

[6] AZoCleantech (2008) Hydrogen Energy-The Perfect Energy Source for the Future? https://www.azocleantech.com/article.aspx?ArticleID=29

[7] Hydrogen Strategy Group (2018) Hydrogen for Australia's Future: A Briefing Paper for the COAG Energy Council. Commonwealth of Australia.

[8] Australian Industry Standards (2020) GAS IRC: Annual Update to Industry Skills Forecast and Proposed Schedule of Work 2020.

https://www.australianindustrystandards.org.au/wp-content/uploads/2020/03/UEG -SF-MERGED-DRAFT.pdf

[9] Australian Industry Standards (2020) PUBLIC SAFETY: Annual Update to Industry Skills Forecast and Proposed Schedule of Work 2020.

https://www.australianindustrystandards.org.au/wp-content/uploads/2020/03/Publi c-Safety-SF-MERGED-DRAFT.pdf

[10] Bezdek, R.H. (2019) The Hydrogen Economy and Jobs of the Future. Renewable Energy and Environmental Sustainability, 4, 1-6.

https://doi.org/10.1051/rees/2018005

[11] H2 Tools (2020) Training. https://h2tools.org/bestpractices/training

[12] Trinder, J.C. (2008) Competency Standards-A Measure of the Quality of a Workforce. The International Archives of the Photogrammetry. Remote Sensing and Spatial Information Sciences, 36, Part B. 